\title{
Rádios Comunitárias como ferramentas na educação não formal, subsidiando Educação Ambiental em regiões urbanas periféricas
}

\author{
Community Radios as tools in non-formal education, subsidizing Environmental Education in \\ peripheral urban regions
}

Radios comunitarias como herramientas en la educación no formal, subvencionando la Educación Ambiental en las regiones urbanas periféricas

\section{Resumo}

A utilização das novas tecnologias de informação e comunicação têm possibilitado uma grande evolução nos processos de ensino-aprendizagem, inclusive na educação não formal. Entre as diversas mídias, a rádio comunitária destaca-se como uma ferramenta com grande potencial para alcançar uma determinada população, atendendo aos seus interesses mais específicos e localizados. A metodologia neste estudo embasou-se em pesquisas bibliográficas e documentais, resultando numa ampla e criteriosa revisão de literatura sobre as rádios comunitárias como forte meio de intercomunicação e educação ambiental não formal, proporcionando conhecimentos e orientações preventivas na preservação do meio ambiente. Foram analisados e discutidos aspectos introdutórios em relação aos ecossistemas educativos, envolvendo as várias mídias, com ênfase na utilização do rádio como elemento de inter-relacionamento entre habitantes de uma região urbana periférica. Esta revisão envolveu análises e discussão em termos de conceitos, histórico, legislações sobre as rádios comunitárias, assim como uma ferramenta educacional não formal em sua contribuição no processo de educação ambiental. Como resultado deste estudo pode-se afiançar que as rádios comunitárias contribuem enormemente para o incentivo nas mudanças comportamentais em relação à educação ambiental, sensibilizando e orientando a formação de cidadãos mais informados, conscientes e, portanto, críticos que saibam lutar por melhorias e bem-estar próprio e da comunidade, por meio do desenvolvimento local com sustentabilidade.

Palavras-chave: Rádio comunitária; Educação não formal; Educação ambiental.

\begin{abstract}
The use of new information and communication technologies has enabled a great evolution in the teaching-learning processes, including in non-formal education. Among the various media, community radio stands out as a tool with great potential to reach a certain population, meeting its most specific and localized interests. The methodology in this study was based on bibliographic and documentary research, resulting in a wide and careful review of the literature on community radio as a strong means of intercommunication and non-formal environmental education, providing preventive knowledge and guidance in the preservation of the environment. Introductory aspects were analyzed and discussed in relation to educational ecosystems, involving the various media, with emphasis on the use of radio as an element of inter-relationship between inhabitants of a peripheral urban region. This review involved analysis and discussion in terms of concepts, history, legislation on community radio, as well as a non-formal educational tool in its contribution to the environmental education process. As a result of this study, it can be said that community radio stations contribute enormously to encouraging behavioural changes in relation to environmental education, sensitizing
\end{abstract}


and guiding the formation of more informed, aware and, therefore, critical citizens who know how to fight for improvements and own well-being and that of the community, through sustainable local development.

Keyword: Community radio; Non-formal education; Environmental education.

\section{Resumen}

El uso de las nuevas tecnologías de la información y la comunicación ha permitido una gran evolución en los procesos de enseñanza-aprendizaje, incluida la educación no formal. Entre los distintos medios, la radio comunitaria se destaca como una herramienta con gran potencial para llegar a una determinada población, atendiendo sus intereses más específicos y localizados. La metodología de este estudio se basó en la investigación bibliográfica y documental, lo que resultó en una amplia y cuidadosa revisión de la literatura sobre las radios comunitarias como un fuerte medio de intercomunicación y educación ambiental no formal, proporcionando conocimiento y orientación preventiva en la preservación ambiental. Se analizaron y discutieron aspectos introductorios en relación a los ecosistemas educativos, involucrando a los distintos medios, con énfasis en el uso de la radio como elemento de interrelación entre habitantes de una región urbana periférica. Esta revisión involucró análisis y discusión en términos de conceptos, historia, legislación sobre radios comunitarias, así como una herramienta educativa no formal en su contribución al proceso de educación ambiental. Como resultado de este estudio se puede constatar que las radios comunitarias contribuyen enormemente a incentivar cambios de comportamiento en relación a la educación ambiental, sensibilizando y orientando la formación de ciudadanos más informados, conscientes y, por tanto, críticos que sepan luchar por mejoras. y bienestar, ser propio y de la comunidad, a través del desarrollo local sostenible.

Palabras clave: Radio comunitária; Educación no formal; Educación ambiental.

\section{Introdução}

O surgimento e aperfeiçoamento das novas tecnologias midiáticas têm possibilitado uma grande evolução nos diversos meios de comunicação, embora em décadas passadas, o rádio tenha sido muitas vezes relegado a um segundo plano, sendo que apenas mais recentemente esteja recuperando sua importância e espaço entre as diversas mídias. Tal redescoberta embasa-se no fato que as ondas do rádio pelas suas características e suas interações com outros meios de comunicação, permitem alcançar e integrar as mais distantes e diversas camadas sociais.

Talvez, uma das mais relevantes características seja a sua capacidade de comunicar-se com milhares de ouvintes de maneira geral e, assim como paralelamente de maneira mais individualizada, dirigindo-se especialmente para uma pessoa ou para um grupo em particular, pois conforme Barbosa Filho (2003) e Mcleish (2001), as palavras, a forma de falar e sobre o que falar, podem ser pensados e estruturados para o ouvinte conforme suas expectativas e particularidades próprias. Uma estação de rádio transmissão em suas várias modalidades, especialmente na forma de rádio comunitária, corresponde a um meio de comunicação que pode proporcionar diversos serviços à população, entre os quais, informação, entretenimento e educação não formal, estabelecendo maior integração e estabelecendo relações mais fortes entre as pessoas em sua região de abrangência, conforme já preconizava Barbosa Filho (2003) e Silva (2010a).

A utilização das novas tecnologias de comunicação midiáticas, entre as quais, as rádios comunitárias despontam como uma excelente ferramenta para alcançar a população de uma determinada comunidade; pois apresentam baixo custo, simplicidade, mobilidade, imediatismo, eficácia, especificidade em seus objetivos, e capacidade de abranger praticamente toda a população, pela sua oralidade, independentemente de seu grau de instrução e nível socioeconômico, além de seu enorme poder de transformação da consciência e do comportamento social. Hoje, suas funções, principalmente pela internet (diversas redes sociais) permitem uma atuação ampla e democrática na unidade geopolítica e social do país e do mundo, permitindo, inclusive o acesso até de populações analfabetas. No geral, com o uso do rádio, torna-se possível o acesso às diversas formas de prestações de serviços, independentemente de sua localização, tais como informações dos acontecimentos e os mais variados eventos no município, estado, país e até sobre o mundo todo, além de atuar como forte elemento de educação e socialização que fortalecem a prática cidadã.

Normalmente, nas programações das rádios comunitárias ocorre uma particularização mais objetiva, buscando atender a um público mais específico, a comunidade; enquanto que nas rádios comerciais ocorre o processo inverso, visando um 
processo de massificação em suas programações. Outra característica importante da rádio comunitária é a pouquíssima presença de conteúdos opinativos, preservando mais o caráter informativo; sem perder, entretanto, as suas linhas de defesas dos interesses da população local (Costa, 2011).

O presente trabalho versa sobre a temática relacionada às rádios comunitárias e suas possíveis contribuições no contexto da educação não formal, especialmente no âmbito da Educação Ambiental (EA), envolvendo estudos embasados em levantamentos bibliográficos, que permitam proposituras de melhorias nos processos de socialização por meio da educomunicação em regiões urbanas periféricas, relacionadas principalmente com o propósito de fornecer maiores informações e conhecimentos sobre questões ambientais e, portanto melhor qualidade de vida.

De forma geral, objetivou-se levantar e apresentar o conceito, histórico, legislação e o status quo sobre a importância das rádios comunitárias como ferramenta midiática no contexto da educação não formal, especialmente em relação aos aspectos de educação ambiental sustentável (meio ambiente, saneamento, etc.) em suas interações com aspectos da qualidade de vida de uma determinada população. Também, abordou-se e discutiu-se aspectos da educação não formal e as contribuições e facilidades que as rádios comunitárias podem efetivar em termos de mudanças comportamentais (conhecimento) no tocante a educação e conscientização sobre o meio ambiente, numa abordagem mais globalizada e universalizada que ensejem didáticas mais preventivas, do que propriamente corretivas em relação ao bem-estar da sociedade.

Foram levantados e analisados artigos que permitam traçar um perfil programático das rádios comunitárias, que contribuem para uma programação local/regional, compostos por orientações educacionais e alternativas viáveis em termos de gestão e desenvolvimento regionais sustentáveis, sem perder de vista as interconexões mais amplas que o assunto exige como salvaguarda das características metropolitana, estadual, federativo e, quiçá do próprio planeta Terra.

Todo esse processo de elaboração prescindiu de uma cuidadosa análise de vários trabalhos pregressos, das quais elaborou-se uma discussão, principalmente qualitativa, o que nos permitiu mensurar a importância desta mídia (rádio comunitária) nas mudanças comportamentais de uma comunidade/região urbana periférica, assim como propor alternativas contributivas no âmbito da educação não formal (via rádio comunitária), que venham maximizar a qualidade de vida (com um viés socioambiental) e maior integração social entre os grupos que compõem uma região, ocasionalmente esquecidas pelo poder público, o que favorece a pobreza e consequentemente a proliferação de diversas mazelas familiares e sociais.

\section{Metodologia}

A metodologia de pesquisa deste trabalho teve uma abordagem de caráter qualitativo, ou seja, não objetivou simplesmente a enumeração ou mensuração de eventos, porém envolveu uma análise mais subjetiva dos dados levantados tais como detalhamento, particularidades e interpretações situacionais relacionados à temática região metropolitana (Marconi \& Lakatos, 2011). Complementarmente, foram acompanhadas por uma abordagem de tipologia analítica, que segundo Marconi \& Lakatos (2011) envolvem estudos e avaliações relativas às informações já existentes, buscando explicações contextuais, assim como explicativas, uma vez que se levantam os fatos, analisam, sintetizam, interpretam e identificam suas causas, visando ampliar generalizações, estruturações e modelos de visão unificada.

Esta proposta metodológica, embasou-se principalmente em pesquisas bibliográficas e documentais, que resultaram numa criteriosa revisão de literatura específica sobre a temática em questão, principalmente de artigos completos em revistas indexadas (nacionais e internacionais), principalmente relativas aos últimos dez anos; assim como de informações e matérias de divulgação em jornais, revistas e documentos com credibilidade, relacionadas ao assunto, obtidas junto a Base nacional de periódicos da CAPES (Web of Science), SCIELO e Google Acadêmico, além de monografias, dissertações e teses na área. 


\section{Rádios Comunitárias}

\section{Conceito}

O Serviço de Radiodifusão Comunitária, ou simplesmente Rádio Comunitária, refere-se a um sistema de radiodifusão sonora, em frequência modulada (FM), de baixa potência (25 Watts), que permite uma cobertura limitada a uma distância com raio de $1 \mathrm{~km}$ a partir da antena de transmissão. Este sistema de radiodifusão foi criado pela Lei 9.612/1998, e regulamentada pelo Decreto 2.615/1998, sendo recentemente alterado em sua capacidade de 25 para 150 watts com a aprovação do Projeto de Lei do Senado (PLS) 513/2017. A exploração desta atividade restringe-se a associações e fundações comunitárias sem fins lucrativos, com sede local e cuja programação deve ser pluralista, abertas à expressão da população local (sem censura) e registrada junto ao Ministério das Comunicações. Cabe a Agência Nacional de Telecomunicações (ANATEL) definir uma frequência para as emissoras prestadoras do Serviço de Radiodifusão Comunitária

A Associação Mundial de Radiodifusores Comunitários (AMARC, 1983) qualifica como rádio comunitária, a rádio rural, a rádio cooperativa, a rádio participativa, a rádio livre, alternativa, popular ou educativa que fomentem a participação dos cidadãos em seus interesses, ou seja, refletem democraticamente os interesses da maioria da comunidade.

É importante observar que a programação de uma rádio comunitária, pelas suas próprias características comunitárias, deve ater-se a propagar atividades de informação, lazer, manifestações culturais, artísticas, folclóricas e outros eventos que contribuam para o desenvolvimento da comunidade local, sem discriminação de raça, religião, sexo, convicções políticopartidárias e condições sociais. Soma-se ainda, as exigências de respeito aos valores éticos e sociais da pessoa e da família, de prestação de serviços de utilidade pública; permitindo ao cidadão o direito de emitir opiniões sobre os assuntos abordados na programação, assim como a manifestação de ideias, propostas, sugestões, reclamações e/ou reivindicações de interesse da comunidade local.

Os patrocínios na forma de apoio cultural, limitados aos estabelecimentos locais, devem restringir-se apenas ao pagamento dos custos relativos à transmissão da programação ou de um programa específico, embora seja permitida por parte da emissora divulgar mensagens institucionais da entidade apoiadora, não mencionando os seus produtos ou prestação de serviços.

As emissoras de rádio e TVs educativas não podem ter objetivos comerciais, embora possam receber recursos e veicular publicidade institucional de entidades de direito público ou privado em condições específicas, assim como a outorga destes serviços não carece de procedimento licitatório.

Uma rádio comunitária não pode utilizar-se da programação de qualquer outra emissora de forma concomitante, exceto quando houver expressa determinação do Governo Federal; assim como é terminantemente vedado veicular qualquer forma de doutrinação, ideias ou sistemas sectários, propagandas comerciais, exceto na forma de apoio cultural e de estabelecimentos de sua área de circunscrição.

Cabe aqui fazer um esclarecimento, para que não haja confusão no entendimento do que é uma rádio educativa e uma rádio comunitária, ambas enquadradas como radiodifusão educativa, o que as distinguem da radiodifusão comercial. No âmbito da radiodifusão educativa vamos encontrar ainda a rádio educativa e a radiodifusão comunitária (rádio comunitária). Os serviços de radiodifusão educativa são concedidos preferencialmente a União Federal, aos Estados e Distrito Federal, aos Municípios e as universidades brasileiras, públicas ou particulares e, sem preferência, também para as fundações particulares com caráter educativo.

Tanto nos sistemas de educação a distância que envolve radiodifusão comercial, como a radiodifusão educativa, especialmente de forma mais recente em relação à rádio comunitária, é interessante apontar que este meio de comunicação possui características específicas, tais como trabalhar conteúdos locais e regionais, além de ser um dos mais democráticos meios de comunicação em termos de acesso, participação e interação. 
Com o advento das modernas inovações tecnológicas digitais (internet, celulares, etc.), o rádio passou a ser relegado a um segundo plano, tanto no uso diário (comercial) como no processo educacional. Nas décadas de 50 e 60, o rádio teve forte representatividade no ensino a distância (pós-ensino por correspondência e antes do ensino pela televisão), sendo um importante meio de interação, tanto em regiões cosmopolitas, como em regiões mais isoladas, especialmente levando notícias e informações, assim como no processo de ensino-aprendizagem (educação e alfabetização de adultos).

Pulleiro (2011), ao analisar as diferentes nomenclaturas utilizadas na América Latina para a rádio comunitária, identifica inicialmente como rádio popular e alternativa, chegando à rádio comunitária e cidadã. Em seu primeiro momento, conforme Pulleiro (2011), entre 1940-1970 a rádio popular e alternativa objetiva expressar o homogêneo, partindo de um setor organizado da classe operária ou da comunidade eclesial.

Posteriormente, a partir de 1980, o termo rádio comunitária procurará "unir o disperso", mas mantendo suas características, entre as quais a ideia de que esta modalidade de rádio deve visar construir e "servir a comunidade", conceito este que busca abranger um espectro maior de atores, envolvendo propósitos como participação, democratização da comunicação, pluralidade/diversidade e minorias (sexuais, étnicas, religiosas etc.).

Nas décadas seguintes, permanecerão ainda estímulos para as rádios comunitárias se constituam em objetos que promovam aspectos democráticos, intermediando os desejos da comunidade com as organizações e os poderes constituídos, embora com tendências de curvar-se mais aos seus projetos político-comunicacional que ao macroprojeto político.

Berti (2017) destaca que houve uma proliferação das rádios comunitários em todo país, fazendo com que cada cidade do Brasil tenha pelo menos uma delas, o que ele entende que é um fenômeno que acontece em função dessas rádios alcançarem lugares onde o discurso politico-partidário ou religioso teria dificuldade de chegar. Já, Sousa et al. (2021) apresentam outro aspecto positivo que está no fato dos integrantes da rádio comunitária estarem inseridas na própria comunidade onde ela funciona, assim o ouvinte e o produtor do conteúdo falam a mesma língua, e são conhecedores dos problemas e das necessidades daquele local.

Essencialmente as rádios comunitárias exercem uma função social importante, pois dá voz aos territórios onde estão localizadas e de fato estão comprometidas com uma melhor qualidade de vida das pessoas que ali vivem, além da salvaguarda dos direitos daqueles que s procuram, ainda que essas emissoras estejam inseridas num contexto onde as demais mídias têm pouco interesse, elas fazem um trabalho de interação importante naquela localidade, com resultados positivos (Galvão \& Vaz Filho, 2020).

Finalmente, podemos afirmar que o conceito de rádios comunitárias resulta de um longo processo histórico, dinâmico e ainda em disputa sobre um modo de se agir politicamente tendo o rádio como instrumento, plataforma ou fim, mas que certamente trata-se de fenômeno vivo, atuante, indeterminado e internamente bastante heterogêneo, conforme Malerba (2017).

\section{Histórico}

No Brasil, quando nos referirmos ao assunto sobre as origens do rádio de maneira geral, podemos dizer que o marco inicial compete a Roquette-Pinto, considerado o pai da radiodifusão brasileira, que juntamente com Henrique Morize, no ano de 1923 fundaram a Rádio Sociedade do Rio de Janeiro, na Academia Brasileira de Ciências, com o slogan "Trabalhar pela cultura dos que vivem em nossa terra e pelo progresso do Brasil”, conforme registrado por Andrelo \& Mantovani (2012).

Inicialmente, o rádio em sua primeira fase no Brasil, era focado principalmente como meio de comunicação voltado para a transmissão de educação e cultura, tendo em vista o direcionamento de seu principal entusiasta e incentivador que foi Roquette-Pinto. Tanto é que em 1936, a função educativa do rádio torna-se oficial, uma vez que Roquette-Pinto fez a doação da Rádio Sociedade do Rio de Janeiro ao Ministério da Educação e Cultura, com o compromisso de que seus ideais em relação a emissora fossem preservados, ou seja, educar o povo brasileiro, nascendo aí o sistema de Rádios Educativas no Brasil. 
Entretanto, em relação a origem das rádios comunitárias, especificamente na América Latina, verifica-se o registro no ano de 1947 na Bolívia, onde grupos de mineiros buscaram uma maneira de comunicação eficaz por meio da radiodifusão, em suas lutas por melhores condições de trabalho, expandindo-se posteriormente para outras regiões entre os camponeses colombianos. Devemos considerar, todavia, que esta forma de comunicação não tinham a amplitude integradora de toda uma comunidade em seus diversos interesses comuns, uma vez que era mais restrita aos interesses trabalhistas dos mineradores e seus dependentes, conforme relata Alves (2005).

No ano de 1983, centenas de representantes e dezenas de ativistas de vários países, reunidos por ocasião do Ano Internacional das Comunicações, promovido pela ONU, fundam a Associação Mundial de Artesãos da Comunicação (AMARC), na cidade de Montreal (Canadá), que posteriormente seria reconhecida como organização não-governamental internacional na $3^{\text {a }}$ Conferência em Manágua, em 1988. De acordo com a AMARC, calcula-se que atualmente existem por volta de 12 mil rádios comunitárias em funcionamento no Brasil, sendo que apenas 4,5 mil estariam autorizadas a funcionar legalmente. Complementarmente, estima-se que existam milhares de rádios comunitárias não oficializadas no país, entre 15 e 20 mil rádios comunitárias "não-legalizadas" conforme assegura Lima e Aguiar Lopes (2007).

Contudo, de fato, em termos de normativas legais, as rádios comunitárias no Brasil têm suas origens por volta de 1987, quando se iniciou as discussões da Assembleia Nacional Constituinte, quando já se vislumbrava a importância do processo de democratização dos meios de comunicação por meio da radiodifusão comunitária, rádios locais e livres, com o objetivo de atender uma comunidade específica. Isto foi confirmado por ocasião da Constituição Federal de 1988, onde observamos um artigo garantindo a liberdade de expressão para as atividades intelectuais, artísticas, científicas e de comunicação geral, livres de qualquer forma de censura ou licença.

Por ocasião do "Fórum Democracia na Comunicação" (FDC) em 1991, fundada pelo professor de Ética e Legislação da ECA/USP, José Carlos Rocha, que ficou conhecido também como Associação Brasileira de Rádio e TV Livre e Comunitária, inicia-se a batalha pela organização do movimento de rádios livres e comunitárias e pelos aspectos jurídicos no processo de regulamentação das rádios comunitárias no Brasil amparados pelos incisos IX, artigo $5^{\circ}$ e no artigo 220 da Constituição Federal Brasileira de 1988, conforme Rocha (2007). Em 1994, o judiciário a $1^{\text {a }}$ vara da Justiça Federal, emitiu sentença favorável para as rádios comunitárias, sendo que em 1996, por ocasião de uma assembleia do Fórum Democracia na Comunicação no Palácio Anchieta (Assembleia Legislativa do Estado de São Paulo), foi formalizado o Anteprojeto de Lei 156/1996.

De fato, as "rádios comunitárias" no Brasil, foram regulamentadas apenas em 1998 (Lei 9.612/1998 e regulamentada pelo Decreto 2.615/1998), sendo que estas rádios em sua grande maioria se localizam nas periferias das metrópoles ou em pequenos municípios, buscando atender interesses mais próximos da comunidade local, conforme especifica Costa (2011). O principal objetivo é a prestação de serviços comunitários às áreas abrangidas pelo rádio, que por sinal é muito restrito. Representa, pois, um importante papel social onde a mesma se insere, e vêm sendo muito utilizada como instrumental educador nestes ambientes, principalmente conscientizando a população sobre seus direitos e deveres, o que muitas vezes faz com que sejam submetidas as pressões governamentais, e inclusive por parte das rádios convencionais, que os veem como concorrentes, embora seus conteúdos sejam bem diferentes de uma emissora comercial (NEAD/UFSJ, 2018a, 2018b).

De acordo com Malerba (2017), frente ao processo de crescimento e proliferação das rádios de baixa potência e da repressão estatal, o processo de normatização e legalização da radiodifusão comunitária no Brasil, especialmente entre 1992/1998, teve como elemento principal a tramitação do projeto de Lei da Informação Democrática (LID). Esta Lei, especificamente em seu artigo $8^{\circ}$ contemplava a vertente livre (regulação mínima) prevendo "liberdade de emissão, transmissão e retransmissão por meio de onda eletromagnética e por fio, para emissoras de rádio e TV de âmbito municipal 
(sem fins lucrativos, de baixa potência, mediante registro em cartório local e excluídas de ingerências religiosas ou políticopartidárias.

\section{Legislação}

A legislação básica que rege o nosso sistema de radiodifusão, trata-se da Lei 9.612/1998, regulamentada pelo Decreto 2.615/1998, que estabelece as normativas do Serviço de Radiodifusão Comunitária (Rádio Comunitária), definindo-a como um sistema de radiodifusão sonora, em frequência modulada (FM), de baixa potência (25 watts), que permite uma cobertura limitada a uma distância com raio de $1 \mathrm{~km}$ a partir da antena de transmissão. Estas normas foram modificadas recentemente, em 2018, pelo Projeto de Lei do Senado (PLS) 513/2017, aumentando a potência das rádios comunitárias de 25 para 150 watts e com torre irradiante não superior a 30 metros de altura.Mais recentemente, em 2018, o Senado aprovou o Projeto de Lei do Senado (PLS) 513/2017 que aumentou a potência das rádios comunitárias, ampliando a sua capacidade de 25 para 150 watts e torre irradiante não superior a 30 metros de altura, com base na justificativa da baixa densidade demográfica de algumas regiões brasileiras, assim como aprovou o aumento do número de canais disponíveis em cada localidade, de um para dois.

Um fato polêmico do ponto de vista de legislação, ocorreu no ano de 2018, quando no apagar das luzes o Governo Federal (MCTIC - Ministério da Ciência, Tecnologia, Inovações e Comunicações) publicou diversas Portarias no dia 31 de dezembro/2018 (DOU, 2018) nas quais 130 rádios comunitárias tiveram suas outorgas extintas ou ficaram perempta em suas concessões, o que oportunizou a algumas entidades de classe considerarem o referido decreto como uma arbitrariedade e, até um retrocesso para os meios de comunicação popular, embora o governo alegasse diversas irregularidades que propiciaram o referido ato de intervenção. Posteriormente, no início do ano seguinte (2019), como justificativa a estas críticas, o MCTIC, esclareceu que essas emissoras cometeram várias infrações da legislação relativas a rádios comunitárias no país.

Por outro lado, em julho de 2019, o Senado discute um Projeto de lei que visa permitir a veiculação de publicidade institucional (pública ou privada) em rádios comunitárias, considerando-se que as rádios comunitárias prestam relevantes serviços comunitários locais, carecendo, entretanto de recursos financeiros para a manutenção de suas atividades sociais, o que poderia ser amenizado por meio de recursos financeiros oriundos desta publicidade paga.

Em relação as estas proposições sobre a regulamentação e uso de publicidades em rádios comunitárias, emergiu então o Projeto de Lei (PL 666/2019), que alterou a Lei 9.612/1998 (Lei de criação da Radiodifusão Comunitária), vindo a permitir a propagação de publicidade institucional de interesse social e a divulgação de atos da administração pública, restrita a 10\% da programação diária. Este Projeto de Lei (PL 666/2019) encontra-se no Plenário aguardando a votação de outros requerimentos que pedem a tramitação conjunta das propostas PLS 55/2016 e da PLS 513/2017, além da solicitação de uma maior discussão junto a Comissão de Transparência, Fiscalização e Controle (CTFC) e na Comissão de Constituição e Justiça (CCJ).

\section{Rádio Comunitária Como Ferramenta Educacional Não Formal}

O entendimento e a plena compreensão por parte da população, dos aspectos políticos e sociais que permeiam a vida comunitária, proporcionam um indicativo seguro do caminho para o conhecimento e domínio de saberes e habilidades, favorecendo o discernimento e a aquisição de habilidades indispensáveis para formação de uma sociedade mais educada, culta, crítica, coesa, e com capacidade de discernimento que venha minimizar as diferenças sociais em nosso país.

Neste contexto, cabe aos educadores a junção de esforços junto ao processo educacional formal e não formal, para todos possam atuar de forma colaborativa com os novos gestores em termos de políticas públicas na formação de cidadãos e profissionais competentes, conforme almejava Roquette-Pinto, em seus primórdios da radiodifusão (há um século) como ferramenta fundamental para a educação em nosso país. 
A educação não-formal, de acordo com Gohn (2005) corresponde a um processo com várias dimensões, tais como aquelas envolvendo "a aprendizagem política, a capacitação laboral (aprendizagem de habilidades e/ou desenvolvimento de potencialidades), a aprendizagem e exercício de práticas comunitária e sociais, a aprendizagem de conteúdos que permitem aos indivíduos ter uma leitura do mundo (compreensão de sua inserção social), a educação midiática"; e até o entendimento de sua inserção e limitações dos recursos naturais em relação ao planeta que vivemos. Sob este prisma, subtende-se que estes espaços não formais de aprendizado podem ser ocupados por diferentes mídias, entre as quais as rádios comunitárias, pelas suas características e peculiaridades, e em especial no nosso estudo aplicando-se conteúdos de aprendizados relacionados ao meio ambiente e saneamento, que venha corroborar para a melhoria da qualidade de vida e principalmente atentar para os fatores preventivos em favor da qualidade de vida de algumas comunidades.

Uma das características positivas mais recomendáveis das rádios comunitárias, além daquelas já citadas, e que favorecem em muito a cumplicidade com o ouvinte, o que o recomenda como forte agente educador sobre questões ambientais é a sua proximidade e credibilidade junto ao público-alvo, além do quê, o cidadão ouvinte pode perfeitamente receber todas as informações sem prejuízo na rotina de seu trabalho.

Em termos de domínio público podemos definir uma rádio comunitária como sendo um serviço de rádio difusão destituídos de fins lucrativos, gerenciado e retroalimentado pela participação da comunidade onde ela se insere, respondendo às necessidades da mesma, em termos de servir e contribuir para o desenvolvimento local de uma maneira progressista, fomentando mudanças sociais, promovendo a democratização por meio da participação comunitária.

Com o crescimento e popularização das TIC e da "internet" em todos os ambientes e locais de aprendizados, interações e convivências sociais, seja nos grandes centros e suas periferias ou em locais longínquos e distantes dos grandes centros urbanos, já é possível o desenvolvimento e utilização de projetos educacionais formais ou informativos, por meio destas novas ferramentas tecnológicas digitais, no caso a "WebRádio", em especial a rádio comunitária, de acordo com Diegues; Coutinho (2010).

Historicamente, quando o rádio começou a surgir na internet, diversos autores começaram a dedicar-se ao estudo desta nova tecnologia de comunicação, entre eles, Prata (2008) que especifica dois modelos de radiofonia, quais sejam, a Radiofonia analógica (transmissões analógicas por meio de irradiação e modulação de ondas eletromagnéticas) e Radiofonia digital (rádio hertzianas com transmissão digital e rádio exclusivamente na internet ou WebRádios). Mesmo considerando-se que existem inúmeros projetos educativos utilizando-se da WebRádio, tanto de maneira formal nas universidades, no ensino básico e secundário; a realidade na educação não formal, utilizando-se de rádio comunitária exige uma programação específica e estreitamente adequada a cada região e objetivos que se pretende alcançar.

Já, para Sadique (2003), a rádio comunitária trata-se de um instrumento para colaborar nos processos de desenvolvimento social e, fundamentalmente na medida do possível, deve representar a ferramenta de comunicação e integração mais importante a ser utilizada pela comunidade. Pois que, uma rádio comunitária deve, portanto, ser parte integrante dos eventos de uma determinada comunidade, uma vez que está envolvida em seus problemas, desafios, sucesso e até fracasso da mesma. Ela deve obrigatoriamente ser usada como uma ferramenta de reflexão, análise, discussão e na busca de soluções para as mais diversas situações e problemas decorrentes do processo de desenvolvimento, de acordo com Chihulume (2016)

Umas das principais exigências, conforme conceituação de uma rádio comunitária, de acordo com Mário et al. (2010) e Mário (2012), é que as rádios comunitárias representem de forma abrangente e esmagadora um meio de comunicação social, de interesse e acessível à comunidade local, onde, por meio da qual ela permuta informações públicas, busca conhecimentos, comunica acontecimentos entre si e inclusive atua como elemento de lazer e entretenimento entre as famílias e a comunidade. 
Ainda, de acordo com Mário et al. (2010) e Mário (2012), o que diferencia as rádios comunitárias de outras formas de comunicação social convencionais são: uso de linguagem local; acessibilidade econômica e disponibilidade de aparelhos e pilhas (receptores); mobilidade do aparelho receptor; escuta coletiva por um único aparelho; superação às barreiras do analfabetismo; maior acessibilidade (distância); e adaptação as culturas onde geralmente prevalecem a oralidade.

Normalmente, este meio de comunicação de massa, é qualificada em sua importância, pois destina-se a uma audiência relativamente grande em seu somatório, normalmente heterogênea e anônima, podendo ser caracterizada como pública (aberta), rápida (momentânea) e transitória, exceto em caso de gravações permanentes com o objetivo de perdurar por longo tempo.

A rádio comunitária permite ainda uma participação ativa e autónoma da população, especialmente por parte de representantes de movimentos sociais e outros representantes de organizações coletivas em seus processos de criação, planejamento e gestão da emissora. Isto significa que ela se embasa em princípios do fortalecimento de maior cidadania (consciência cidadã), aperfeiçoando e recriando os conhecimentos oriundos da comunicação popular, comunitária e alternativa, conforme já explicitado por Costa (2011).

Uma rádio comunitária deve ter como premissa básica servir como instrumento de "livre divulgação de ideias, atividades culturais, tradições e costumes" na comunidade onde se localiza, por meio de uma linguagem acessível e com uma programação de qualidade e, sobretudo muita criatividade, endossando considerações de Souza et al. (2005). Neste aspecto, efetivamente o rádio representa desde os seus primórdios um forte elemento contributivo no processo de passar informações e agregar conhecimento junto a população ouvinte, desde ao mais simples até ao mais erudito cidadão.

Existem inúmeras possibilidades de trabalhar esta ferramenta com os aprendizes ouvintes, dependendo do nível de conhecimento de cada grupo, mas no tocante a uma comunidade heterogênea e diversificada podem ser utilizadas desde metodologias/projetos mais simples como "simplesmente ouvir" determinadas orientações pelas rádios, até a elaboração de atividades práticas (botar a mão na massa" por meio de atividades coletivas sob orientação e supervisão de lideranças já treinadas, tendo como elo comunicador programas conduzidas pelo rádio.

Em seu processo de globalização, o rádio, especialmente na modalidade de rádio comunitária dentro de suas limitações, permite ao ouvinte uma maior aderência e inserção da sua realidade diária, o que representa uma alternativa de socialização e maior interatividade entre si.

Pelo exposto, não restam dúvidas quanto a importância desta modalidade de comunicação midiática, simples e objetiva, que proporcionam inúmeros benefícios locais, tais como rapidez e agilidade nas informações veiculadas por elas; muitas vezes corriqueiras, mas de grande importância para a região e seus moradores. Todas estas características contribuem para uma maior autonomia dos cidadãos comuns, promovendo informações, conhecimentos e possibilitando livre fluxo de pensamentos e ideias, o que oportuniza maior liberdade de expressão, além de favorecer e consolidar o processo democrático.

Efetivamente, é significativo que em qualquer grupamento com interesses comuns, como numa comunidade distante (periferia) até os grandes centros urbanos, possa haver ferramentas de comunicação (não formal) imediata e voltada ao nosso dia a dia, tais como questões informativas de segurança, acontecimentos, eventos, estratégias de preventivas de ações, entremeadas de entretenimentos e outras atividades de lazer. Para tanto, desenvolver e administrar um projeto educacional que almeje popularizar e democratizar a educação ambiental para uma população mais simples e muitas vezes com pouca instrução, requer enorme disponibilidade e dedicação de toda uma equipe, que se disponha em coordenar a programação.

$\mathrm{Na}$ área de atuação ligada especialmente as questões ambientais e, portanto, à qualidade de vida, que em seus objetivos de efetividade deve alcançar todos os rincões de nossa pátria; a rádio comunitária como ferramenta de educação não formal representa um importante elo de comunicação pelas suas características e múltiplas possibilidades e empregabilidade no processo integrado de educação globalizado. 


\section{Contribuição da Rádio Comunitária na Educação Ambiental}

A Educação ambiental propagada pelo rádio objetiva fomentar a absorção de conhecimentos ambientais num processo educativo não-formal, tais como valores socioambientais sustentáveis, incentivar comportamentos e hábitos saudáveis em relação a conservação dos recursos naturais, disseminar conhecimento ambientais para que uma população se transforme em agentes sociais conscientes como defensores da preservação e proteção do meio ambiente.

Ampliando o leque de funções da rádio comunitária podemos citar a sua grande importância que a mesma desempenha em suas funções sociais em seu processo de transformação e evolução, pois possibilita inúmeras formas de debates e assuntos, disponibilizando a exposição de assuntos e problemas da comunidade, assim como a discussão e busca de soluções práticas, contribuindo e promovendo as mudanças necessárias para o desenvolvimento cultural, socioeconômico e socioambiental da população.

Embora com algumas dificuldades, os dados na literatura têm demonstrado que a utilização das inúmeras ferramentas midiáticas na promoção da educação ambiental tem sofrido um sensível aumento, pelas suas características especificas de rapidez, baixos custos e alcance populacional, embora as TIC como a robótica educacional, o rádio e o celular ainda representem números poucos significativos em relação ao ensino das salvaguardas ambientais.

Soares e Vasconcelos (2018) efetuaram estudos relacionados ao tema, por meio de uma ampla revisão sistemática da literatura, buscando mapear os estudos sobre a utilização das TIC como ferramenta em Educação Ambiental, resultando na confirmação que atualmente existem inúmeras tecnologias de informação e comunicação que são utilizadas na educação ambiental. Talvez, ainda esteja faltando um embasamento metodológico específico para um maior desenvolvimento destas práticas, de forma mais técnica e oficial, que poderão ser desencadeadas à partir de estudos que procurem especificar de forma concreta as funções e características destas tecnologias digitais midiáticas, tornando-as mais efetivas e direcionadas pedagogicamente aos processos de ensino-aprendizagem, especialmente sobre educação ambiental, conforme especificadas por Soares e Vasconcelos (2018).

Almeida e Moita (2015), descrevem que a utilização das TIC, em suas diversas modalidades auxiliam muito no processo de aprendizado, permitindo aos professores a apresentação diferenciada dos conteúdos, sobre as quais poderíamos validar para as diversas mídias, inclusive as rádios e em especial das rádios comunitárias em relação as temáticas ambientais, seja para divulgação preventivas das danosas ações antrópicas, seja para divulgar conhecimento no processo de implementação da educação ambiental, também de acordo com Soares \& Vasconcelos (2018).

É de suma importância também, lembrar que de acordo com Mueller et al. (2012) estas práticas pedagógicas promotoras da educação ambiental são elementos coadjuvantes na recuperação dos saberes locais, sejam eles econômicos, ambientais, culturais e/ou sociais; representativos de uma comunidade, reinserindo-os em seu espaço e contexto, por meio desta prática pedagógica, desenvolvendo-o e integrando-o, através de seus saberes e conhecimentos, conforme as suas próprias vocações.

Volpato (2008) explicita que qualquer forma de aprendizado ou modalidade educacional pode ser adquirida de inúmeras maneiras e, entre elas pela utilização das diferentes mídias como o rádio, que representa um forte elemento de formação da opinião pública, o que pode ser utilizado para estimular a conscientização ambiental por meio da veiculação de projetos educacionais relacionados ao meio ambiente, com responsabilidade de uma programação consciente e educativa.

De forma complementar, Silva (2010a) preconizou que a Educação Ambiental seria o melhor caminho para a conscientização da população em relação ao tema, enquanto que os meios de comunicação seriam as principais ferramentas para a concretização desse processo educativo, enfatizando que o rádio representaria um instrumento especial de divulgação e propagação destes conhecimentos, de forma simples e de baixo custo, objetivando a formação e conscientização dos cidadãos nos temas ambientais. 
Paralelamente, deve-se lembrar que em 1972, por ocasião da Conferência da Organização das Nações Unidas para o Meio Ambiente Humano (ONU), realizada Estocolmo (Suécia), ficou definido que a Educação Ambiental deveria possuir uma abordagem multidisciplinar em todos os níveis de ensino, inclusive naquele não formal, em busca da conscientização de toda população mundial nas questões de educação e preservação da natureza. Posteriormente, em 1975, foi criado pela UNESCO o Programa Internacional de Educação Ambiental (PIEA), cujo escopo recomendava as principais ações a serem desenvolvidas pelos países membros, com ênfase aos cuidados com o meio natural e artificial, considerando-se os fatores ecológicos, políticos, econômicos, sociais, culturais e estéticos. Definia ainda que a Educação Ambiental deveria ser contínua, multidisciplinar, integrada com as diferenças regionais e com o objetivo de formar uma consciência coletiva, capaz de compreender a importância do meio ambiente no papel da preservação da vida em suas diversas formas.

Nestes termos, em relação ao Brasil, contamos com a Política Nacional do Meio Ambiente (Lei $n^{\circ}$ 6.938/81) onde preconiza-se que a Educação Ambiental é indispensável à preservação, melhoria e recuperação da qualidade ambiental de vida, visando assegurar, no país, condições de desenvolvimento socioeconômico aos interesses da segurança nacional e à proteção da dignidade humana (Brasil, 1981). Ainda, conforme o Programa Nacional do Meio Ambiente, a Educação Ambiental deve orientar maior conscientização da população no sentido da preservação e conservação de nossos recursos naturais renováveis, além de fomentar e desenvolver aprendizados e boas práticas ambientais.

O trabalho de Silva (2010b) trata-se de uma proposta sobre a utilização dos meios de comunicação, especificamente o rádio, como ferramenta para a educação não-formal, tendo como área de conhecimento e aprendizado a educação ambiental. Utilizando-se de ferramentas midiáticas, no caso rádio, como instrumental no processo de educação não-formal, Silva (2010b) idealizou uma produção radiofônica voltada para a educação ambiental (Programa Sinal Verde), envolvendo características híbrida, mesclando objetivos educativos, culturais, informativas e entretenimento.

Entretanto, o alvo principal deste projeto buscava a inserção de questões ambientais no dia a dia de jovens, como forma permanente de reflexões, práticas e participações interativas. Na prática, buscava-se fomentar a educação ambiental dentro de um processo educativo não-formal, conectando a comunidade junto aos valores socioambientais sustentáveis, incentivando hábitos e comportamentos saudáveis, com as salvaguardas dos recursos naturais, divulgando conhecimentos e aprendizados para a formação de agentes sociais conscientes e com visão práticas de sustentabilidade em relação à preservação e proteção ambiental.

De acordo com Souza (2005), o rádio utilizado como ferramenta de educação ambiental, caracteriza-se pelo ensino de forma alternativa daquela do sistema da educação formal, atuando muitas vezes como mediador de conflitos ou canal de denúncias pertinentes aos problemas e crimes ambientais, o que pode ser aplicado também de forma mais eficiente em relação as rádios comunitárias. Isto explica-se, pois, uma mensagem radiofônica transmitida por meio de um texto falado se torna algo presente, reforçados pelos efeitos sonoros que estimulam a memorização dos conteúdos, o que nos garante que o rádio pode ser um forte componente no processo de conscientização e ações individuais e que acabam por refletir sobre a qualidade ambiental e sustentabilidade do planeta como um todo, conforme Silva (2010b)

Considerando-se os aspectos longamente apresentados e discutidos, de que os meios de comunicação, utilizando-se das mídias, especialmente pelas ondas das rádios comunitárias, e que influenciam fortemente na formação opinativa do indivíduo, assim como no pensamento social, é recomendável que tais meios de educomunicação devem ser melhores aproveitados como agente formador não formal em qualquer processo educacional, e em especial na educação ambiental. Entretanto, é preciso considerar também a importância do papel da atuação das instituições educadoras no processo de educação formal, envolvidas em seu contexto interdisciplinar no tocante ao ensino do meio ambiente e suas inter-relações socioeconômicas, conforme preconiza Silva (2010). 
Os problemas ambientais estão dispersos praticamente em todos os recantos e espaços ocupados pelo homem, levando-se em conta a afirmativa de Silveira e Lorencini (2011), de que o impacto ambiental pode ser corresponde a qualquer alteração no meio ambiente, resultantes direta ou indiretamente de atividades antrópicas, tem sido ocasionado pela presença da espécie humana nos mais diversos ambientes do planeta.

Conforme dados da Pesquisa Nacional por Amostra de Domicílios - PNAD/IBGE (2015), no Brasil, cerca de 84,7\% da população habita no meio urbano, inclusive em condições precárias, principalmente nas grandes periferias, em ambientes sem mínimas condições de segurança, muitas vezes provocadas e agravadas por problemas ambientais provocadas pelo mesmo homem. Neste contexto, como componente contributivo para minimizar agravamentos de catástrofes, surge a Educação Ambiental (EA) em suas diversas modalidades, entre as quais citamos as rádios comunitárias como elemento de educação ambiental de baixo custo, grande rapidez e de ampla abrangência, que pode atuar preventivamente, no momento de eventos problemáticos (coordenando/orientando) e inclusive corretivamente pós-eventos, reestabelecendo a situação de normalidade.

Evidentemente, os grandes problemas ambientais não são repentinos, mas são resultados de longos períodos de abusos e contravenções ambientais que acabam por resultar em grandes catástrofes, como resposta da natureza em seu ciclo natural. A resolução na prevenção destes eventos envolve questões de políticas públicas, planejamento, financiamentos, educacionais, históricas, socioeconômicas, ecológicas, entre outras, e sobretudo a participação de uma sociedade educada e informada em termos de convivência social e ambiental, endossando citações de Xavier et al. (2016). Esta carência de educação, a desinformação e a falta de interesse da população, referentes a estas questões, seja de educação formal ou informal, representam a principal dificuldade em relação à produção de espaços ambientalmente perigosos e de riscos para toda a sociedade.

Além dos diversos processos, metodologias e ferramentas educacionais em todos os segmentos de aprendizado, a rádio comunitária surge como mais uma ferramenta atual no processo educacional brasileiro, principalmente no tocante da educação formal e para população de regiões periféricas. Tais ferramentas, por si só, seriam insuficientes, pois é preciso agregar e integrar várias metodologias, deixando aquelas de caráter demasiadamente conservadoras, onde os problemas ambientais urbanos não devidamente diagnosticadas, discutidas e encaminhadas aos órgãos competentes para solução, conforme já discutidos por Xavier et al. (2016).

Como exemplo de rádios comunitárias e educação ambiental é o trabalho de Steinbrenner et al. (2015), que elaboraram estudos nos quais fizeram o mapeamento digital das rádios comunitárias na Amazônia Legal, envolvidos com projetos de pesquisas relacionadas ao desenvolvimento dos cidadãos com sustentabilidade socioambiental. Mapearam cerca de 498 emissoras licenciadas, situadas em 436 municípios amazônicos, associando também a existência de Unidades de Conservação, Terras Indígenas e de Usinas Hidrelétricas nestes municípios. Neste estudo objetivou avaliar o papel da comunicação comunitária como uma ferramenta contra hegemonia midiática, buscando fortalecer a representatividade dos grupos locais em decisões afetos ao seu bem-estar, assim como contribuir para a conservação e sustentabilidade socioambiental de sua área territorial. Os resultados, com boas perspectivas socioambiental das rádios comunitárias da região amazônica, estão disponibilizadas num mapa digital na "internet", proporcionando uma maior compreensão e importância e do papel que as mesmas representam, enquanto instrumento de comunicação e educação cidadã e socioambiental para a estruturação e garantia do processo democrático atrelados ao desenvolvimento sustentável da Amazônia, conforme preconizado por Steinbrenner et al. (2015).

A necessidade de uma educação e maior consciência ambiental, que resultem em sustentabilidade e bem-estar para nossa sociedade globalizada, têm sido demonstradas por vários autores, em que pese as argumentações tal como a de Silva (2010a) preconiza que: "A dinâmica destrutiva do sistema se mantém e se aprofunda a despeito do avanço das discussões sobre a necessidade de preservação/conservação dos bens naturais e dos investimentos nesse campo". Esta observação é resultante 
de uma análise crítica de nossa realidade onde identificamos a uma competição desenfreada entre nações pelo poder e pela ganância, que desembocam na utilização desequilibrada dos recursos naturais e outras atividades antrópicas que acabam por provocar situações de desigualdades sociais, pobreza e diversas outras mazelas sociais, conforme já preconizava Leff (2006) e Loureiro (2012a, b).

Nesta expectativa, a educação ambiental evidencia-se como um dos instrumentos mais efetivos para construção de novos saberes e conhecimentos, ensejando novos valores e práticas ambientais saudáveis e sustentáveis para todos, a partir de uma pequena célula para alcançar todo o planeta. Além do que, estas premissas atendem a Constituição Federal de 1988 que especifica em seu Artigo 205 que: Art. 205- A educação, direito de todos e dever do estado e da família, será promovida e incentivada com a colaboração da sociedade, visando ao pleno desenvolvimento da pessoa, seu preparo para o exercício da cidadania e sua qualificação para o trabalho, premissas também apresentadas e discutidas por Hayashi \& Silva (2015a, b, c).

Desta forma, confirma-se que a utilização da rádio comunitária contribui enormemente para o incentivo nas mudanças comportamentais em relação a educação ambiental, de forma a sensibilizara nossa sociedade, pois orientam a formação de cidadãos mais informados e portando críticos, que saibam lutar por melhorias e bem-estar próprio e da comunidade, por meio do desenvolvimento local.

Tais considerações são reafirmadas por Mueller et al. (2012), quando cita que estas práticas pedagógicas relacionadas a EA "recuperam os saberes locais econômicos, ambientais, culturais e sociais, presentes numa comunidade, desenvolvendo-os por meio do aprendizado (conhecimento) não formal consoante as suas vocações, proporcionando o desenvolvimento local.

\section{Considerações Finais}

Em mais de duas décadas desde a aprovação, a Lei da Radiodifusão Comunitária (Lei 9.612/98) não restam dúvidas em termos quantitativos sobre o crescimento das rádios comunitárias em suas diversas formas de atuação em frequência modulada (FM), com baixa potência (até 25 wats) e reduzido alcance (1 km de raio), e sempre vinculadas as associações comunitárias sem fins lucrativos e registradas pelo Ministério das Comunicações (MiniCom).

Isso é decorrente das inúmeras e diversas formas de pressões a que são submetidas as emissoras comunitárias, tanto em suas normativas de regulamentação, quanto para manterem-se no ar, dado ao caráter voluntário de seus participantes. Algumas destas questões limitantes impostas pela Lei 9.612/1998, tais como alcance, potência e frequência, de associação por meio de rede, além do modelo de gestão financeira, foram parcialmente superadas mediantes algumas novas proposituras de legislação recentes.

Deve-se anotar também a enorme burocracia e falta de políticas públicas efetivas que permeiam o processo de legalização das rádios comunitárias, num sistema arcaico e patrimonialista, que tendem a favorecer apadrinhamentos políticos e/ou religiosos, que acabam por repetir os modelos de rádios comerciais, nada possuindo de interesse comunitário, conforme asseguram Steinbrenner et al. (2015).

Ao longo deste estudo e levantamentos, pode-se afiançar que as rádios comunitárias representam de certa forma um acontecimento de comunicação em desenvolvimento extremamente crescente e vigoroso, especialmente em mais periféricas das grandes metrópoles, assim como em regiões mais isoladas do planeta.

Por outro lado, é interessante observar que pelo mesmo motivo das mesmas atuarem em áreas periféricas, comandadas por grupos da própria comunidade, estas rádios eventualmente pouco impactam a agenda política ou mesmo lutam por maior audiência, o que gera um paradoxo, comentados por Steinbrenner et al. (2015). Explicando, elas constituem-se num fenômeno em ascensão, em termos sociais e políticos, entretanto pouco conhecido por grande parte do grande público, invisível para além de suas bases ou segmentos diretamente antagônicos e não reconhecido de fato pelos tomadores de decisão. 
Mesmo considerando-se as características de unidirecionalidade do rádio, ela permite o estímulo de habilidades de audição, interpretação, elaboração mental, construção de cenários imaginários, excluindo o ouvinte de seu papel passivo no processo de abertura e oportunidades de acesso aos novos aprendizados e conhecimentos, aliados a diversas outras fontes de informações, todos a serviço do processo educacional.

$\mathrm{Na}$ atualidade, a Educação Ambiental constitui-se num fator fundamental de bem-estar em nossa convivência em sociedade, inclusive como base e garantia da nossa própria sobrevivência no planeta, pois certamente se seguirmos os descaminhos desvairados do consumismo que temos trilhado nas últimas décadas, a natureza cobrará a sua fatura, acionando seus mecanismos de controle populacional de forma natural, como sempre o fez, ao longo de seu processo evolutivo.

Neste processo de desenvolvimento, objetivando produção de bens de consumo e ganhos de capital, para atender as demandas de nosso crescimento populacional em termos de alimentação e bem-estar, nossa sociedade interfere de maneira insustentável nos processos de interações ecológicas ambientais da natureza.

Todas estas intervenções antrópicas, provocam transformações ambientais ao longo do tempo, com graves consequências à sustentabilidade de nossos recursos naturais, entre as quais citamos o efeito estufa, poluição do ar, água e solo, aquecimento global, perda de florestas, monocultura, desertificação e fatalmente a extinção de espécies, inclusive a do homem principalmente pela falta de alimentos, proliferação de doenças, guerras, entre outras.

Diante destas circunstâncias, o momento exige ampla discussões e reflexões sobre a realidade das ações do homem em relação às questões ambientais, que permeiam, inclusive, a própria sobrevivência de todos os seres vivos no planeta.

Torna-se, portanto imprescindível e necessário que o mundo moderno busque alternativas e tomadas de ações práticas, para que haja uma interação menos destruidora e mais positiva com a natureza. Uma destas tomadas de decisões mais importante nesta caminhada seria mudanças comportamentais da espécie humana em relação ao seu sistema de produção e maneira de enxergar o meio ambiente onde vive, o que só conseguiremos por meio de um forte e eficaz processo de educação com um forte viés ambiental, que mobilize toda a sociedade global.

Entretanto, tais assertivas já é de domínio público e de consenso entre os estudiosos da área, pois que, na prática necessitamos de um maior envolvimento da comunidade nesta caminhada, a partir de ações que promovam o surgimento e entendimento de novos valores de sustentabilidade. Aqui entra as diferentes formas de aprendizado e educação ambiental, inclusive com o uso das novas tecnologias de comunicação, no caos em estudo as rádios comunitárias como elemento que alcançam de forma democrática uma ampla parcela da população, independentemente de suas diferenças sociais e econômicas.

Mesmo considerando-se as rádios comunitárias excelente meio de comunicação entre os indivíduos de uma determinada comunidade, estando em forte crescimento nas regiões periféricas das regiões metropolitanas, assim como nos distantes povoados deste imenso país; muitas vezes este meio de comunicação não impactam as políticas públicas governamentais. Talvez, justamente pela sua atuação periférica e pela sua programação de gestão voluntária, as rádios comunitárias muitas vezes não conseguem vestir-se de uma ousadia maior em seus propósitos e influenciar algumas diretrizes em âmbito nacional, atendendo prioritariamente interesses mais localizados o que a exclui de envolver-se em questões maiores. Entretanto, esta visão de escopo e propósitos mais localizados para um espectro mais abrangente em termos de políticas públicas, indicam mudanças no curto e médio prazo, principalmente se forem tomadas medidas inovadoras de gestão e de propostas educacionais meritocráticas.

Resumidamente, numa análise mais sucinta e direta, a partir dos dados aqui discutidos, dentro de uma perspectiva de educação socioambiental por meio da utilização de rádios comunitárias, pode-se garantir que esta forma de tecnologia midiática, embora aparentemente ultrapassada, mostra-se como um forte instrumento de agregação e integração comunitária em seus diversos aspectos e interesses, inclusive educacional não formal, no que diz respeito a educação ambiental de uma determinada comunidade. Nesta expectativa, este trabalho vem contribuir para discutir uma ferramenta midiática muito 
utilizada em décadas passadas, mas que em período recente estava sendo esquecida e relegada ao ostracismo, mas que ressurge como uma forte opção de baixo custo e de excepcional alcance em regiões periféricas de comunidades mais carentes, além de subsidiar embasamentos bibliográficos teóricos sobre a temática em pauta, inclusive para diversas outras mídias.

\section{Referências}

Almeida, F. L., \& Moita, F. M. G. C. (2015). Biologando: a tecnologia digital no ensino de Biologia. Revista Internacional de Aprendizaje em Ciencia, Matemáticas y Tecnologia. UEPB. 2(2), 91-105. https://journals.eagora.org/revEDUMAT/article/view/918/483. https://doi.org/10.37467/gka-reveduma t.v2.918“.

Alves, A. M. V. (2005) As Rádios Comunitárias em Moçambique: Estudo de caso. Dissertação de Mestrado em Estudos Africanos, FLUP.

AMARC. (1983) Associação Mundial de Radiodifusores Comunitários. http://amarcbrasil.org/conceito/

Andrelo, R., \& Mantovani, T. M. M. (2012) O rádio na educação à distância. Observatório da Imprensa, 11 de outubro de 2012 , Edição 677. http://www.observatoriodaimprensa.com.br/diretorio-academico/ed677-o-radio-na-educacao-a-distancia/

Barbosa Filho, A. (2003) Gêneros radiofônicos: os formatos e os programas de áudio. Paulinas, 2003. 158 p.

Brasil. (1981) Lei ${ }^{\circ}$ 6.938/81. Lei de Política Nacional do Meio Ambiente no. 6.938/81, de 31 de agosto de 1981. [PNMA]. Estabelece a política nacional do meio ambiente. http://www.lex.com.br/doc_90026_LEI_N_6938_DE_31_DE_AGOSTO_DE_1981.aspx.“.

Brasil. (1988) Constituição da República Federativa do Brasil. https://www2.senado.leg.br/bdsf/bitstream /handle/id/518231/CF88_Livro_EC91_2016.pdf

Brasil. (1996) Anteprojeto de Lei 156/1996. Rádios Comunitárias - as rádios. http://www.saopaulo.sp.leg. br/especiaiscmsp/conheca-as-radios-comunitariasde-sao-paulo/

Brasil. Decreto $\mathrm{n}^{\mathrm{o}}$ 2.615, de 3 de junho de 1998. (1998) Aprova o Regulamento do Serviço de Radiodifusão Comunitária. http://www.mctic.gov.br/mctic/opencms /legislacao/decretos/Decreto_n_2615_de_02061998.html

Brasil. (1998) Lei nº 9.612, de 19 de fevereiro de 1998. Institui o Serviço de Radiodifusão Comunitária e dá outras providências. http://www.planalto.gov.br /ccivil_03/leis/L9612.htm

Brasil. (2016) Projeto de Lei do Senado n ${ }^{\circ}$ 55, de 2016. Acrescenta o art. 18-A à Lei no 9.612, de 19 de fevereiro de 1998 , para permitir o custeio da operação de rádios comunitárias através da venda de publicidade e propaganda comercial. https://www25.senado.leg.br /web/atividade/materias/-/materia/124948

Brasil. (2017) Projeto de Lei do Senado $\mathrm{n}^{\circ}$ 513, de 2017. Altera a Lei $\mathrm{n}^{\circ} \quad 9.612$, de 19 de fevereiro de 1998 . https://www25.senado.leg.br/web/atividade/materias/-/materia /132042

Brasil. (2019) Projeto de Lei n 666, de 2019. Altera a Lei 9.612, de 19 de fevereiro de 1998, que "Institui o Serviço de Radiodifusão Comunitária", para permitir a veiculação de publicidade institucional. https://www25. senado.leg.br/web/atividade/materias/-/materia/135185

Carvalho Berti, O. M. (2017) Rádios comunitárias brasileiras na Internet. Faces e interfaces da democratização da comunicação comunitária em tempos de tecnologias atuais no Nordeste. PAULUS: Revista de Comunicação da FAPCOM, 1(2), 111-120.

Chihulume, J. (2016) Funcionamento e desafios das rádios comunitárias-estudo de caso da rádio comunitária de Homoíne. Mestrado em Desenvolvimento Rural. Faculdade de Agronomia e Engenharia Florestal, 85p.

Costa, R. A. (2011) Importância das Rádios Comunitárias para as Comunidades em que Estão Inseridas. Revista Anagrama: Revista Científica Interdisciplinar da Graduação. USP, Cidade Universitária. 3, 1-10. 2011. https://www.revistas. usp.br/anagrama/article/ viewFile/35525/38244

Diegues, V., \& Coutinho, C. (2010) WebRádio educativa: produção e utilização de Podcasts em experiências educomunicativas. Prisma.com: Revista de Ciências Tecnologias de Informação e Comunicação, 13, 1-23, 2010. https://ojs.letras.up.pt/index.php/ prismacom /article/view/2000

DOU Diário Oficial da União. 31 Dez 2018, Seção 1, Página 18. 2018. https://www.jusbrasil.com.br/diarios/223178463/dou-secao-1-31-12-2018-pg-18

Galvão, L. C. J., \& Vaz Filho, P. S. (2020) Vozes da rádio comunitária: O papel da Heliópolis FM na luta contra a Covid-19 na cidade de São Paulo. Radiofonias - Revista de Estudos em Mídia Sonora, 11(3), 105-132, 2020.

Gohn, M. G. Educação não-formal e cultura política. Cortez, (3a ed.), 128p.

Hayashi, C., \& Silva, L. H. de A. (2015a) A gestão ambiental e sustentabilidade no Brasil. XI Fórum Ambiental da Alta Paulista, Periódico Eletrônico Fórum Ambiental da Alta Paulista. 11(7), 37-51.

Hayashi, C., \& Silva, L. H. de A. (2015b) Instrumentos de políticas públicas em gestão ambiental e sustentabilidade no Brasil. XI Fórum Ambiental da Alta Paulista, Periódico Eletrônico Fórum Ambiental da Alta Paulista, 11(7), 52-64.

Hayashi, C., \& Silva, L. H. de A. (2015c) Políticas públicas de gestão ambiental e sustentabilidade: um estudo de caso do município de Ribeirão Preto, SP. XI Fórum Ambiental da Alta Paulista, Periódico Eletrônico Fórum Ambiental da Alta Paulista, 11(7), 65-79,

IBGE. Pesquisa Nacional por Amostra de Domicílios - PNAD/IBGE (2015). <https://biblioteca.ibge.gov.br/visualizacao/livros/liv98887.pdf> Acesso em 03 jul 2021. 
Leff, E. Epistemologia ambiental. Tradução de Sandra Valenzuela. (4a ed.).

Lima, V. A., \& Lopes, C. (2007) Rádios comunitárias: coronelismo eletrônico de novo tipo (1999-2004). Observatório da Imprensa, Projor, 2007. 186p. http://observatoriodaimprensa.com.br/download/Coronelismo_eletronico_de_novo_tipo.pdf

Loureiro, C. F. B. (2012a) Sustentabilidade e Educação: Um olhar da ecologia política. Cortez Editora.

Loureiro, C. F. B. (2012b) Trajetória e Fundamentos da Educação Ambiental. Cortez Editora.

Malerba, J. P. (2017) Por uma genealogia das rádios comunitárias brasileiras. Logos - Comunicação e Universidade: Rádio nas bordas - Cartografias da radiodifusão comunitária, livre e alternativa. 24(1), 08-22.

Marconi, M. A., \& Lakatos, E. M. (2011). Metodologia do trabalho científico: procedimentos básicos, pesquisa bibliográfica, projeto e relatório publicações e trabalhos científicos. (7a ed.), Atlas, 277p.

Mário, T. V., Minnie, J., \& Bussiek, H. (2010) Rádios Pública em África - Moçambique, Projecto de Monitoria e Advogacia em África AfriMap/OSFSA/OSIMP, África do Sul, Compress. 2010. http://www.afrimap.org/english/images/ report/Moz\%20Broadcasting \% 20Survey\% 20Porto\%20Web.pdf

Mário, T. V. (2012) Guia de Reforma das Políticas e Legislação da Comunicação Social em Moçambique, Ed. Frieddrich Ebert Stiftung, Impressão Ciedima, Maputo.

MCleish, R. (2001) Produção de Rádio. Summus.

Mueller et al. (2012) Educação Para o Desenvolvimento Local: Uma Alternativa Para o Desenvolvimento de Municípios. Revista Eletrônica em Gestão, Educação e Tecnologia Ambiental. REGET/UFSM. 5(5), 883-903.

NEAD/UFSJ. (2018a) Os Diferentes Serviços de Radiodifusão. Apostila da Disciplina Serviços de Radiodifusão - Unidade 03, Curso de Especialização em Mídias na Educação), NEAD/UFSJ. 09p.

NEAD/UFSJ. (2018b) O rádio como instrumento para governar. Apostila da Disciplina Serviços de Radiodifusão - Unidade 02, Curso de Especialização em Mídias na Educação), NEAD/UFSJ. 04p.

Prata, N. (2008) WebRadio: novos gêneros, novas formas de interação. 2008. 395f. Dissertação (Doutorado) - Universidade Federal de Minas Gerais, Faculdade de Letras UFMG.

Pulleiro, A. (2011) La radio alternativa en América Latina: debates y desplazamientos en la década de 1990. Buenos Aires: UBA. Facultad de Ciencias Sociales. Carrera de Ciencias de la Comunicación. 178p. http://comunicacion.sociales.uba.ar/wp-content/uploads/sites/16/2013/02/Pulleiro.pdf

Rocha, J. C. (2007) Identidade, magia e poder da rádio comunitária. In Mídia e violência urbana no Brasil. UNESCO, Viva Rio, 92 p.

Sadique, F. M. (2003) Temático para as Rádios Comunitárias. UNESCO/UNDP. Grupo Editorial de Agricultura; 2003

Silva, M. G. (2010a) Questão ambiental e desenvolvimento sustentável: um desafio ético-político ao serviço social. Cortez Editora, 256p.

Silva, R. C. da (2010b) Uma proposta de educação ambiental para o rádio. Revista PJ: Br Jornalismo Brasileiro, edição 13. http://www2.eca.usp.br /pjbr/arquivos/monografias13h.htm

Silveira, D. I., \& Lorencini Jr, A. (2011) Estudo sobre a temática dos impactos ambientais urbanos na coleção de livros didáticos: Projeto Araribá de Geografia. VIII Encontro Nacional de Pesquisa em Educação em Ciências. Universidade Estadual de Londrina.

Soares, W. N., \& Vasconcelos, F. C. W. (2018) A utilização de tecnologias de informação e comunicação como recurso didático para a promoção da educação ambiental. Revista Tecnologias na Educação, 10(25), 1-16, 2018.

Sousa, E. S. B., Lopes, W. G. R., \& Carvalho Berti, O. M. (2021) A rádio comunitária eo desenvolvimento sustentável: estudo no semiárido do Piauí, Brasil. Espacio abierto: cuaderno venezolano de sociología, 30(1), 33-53.

Souza, M. V. et al. (2005) Rádios Comunitárias do Vale do Itajaí: controvérsia legal, sociopolítica e ideológica. 2005 - Universidade do Vale do Itajaí.

Steinbrenner, R. M. A., Velloso, B. L., \& Cunha, L. C. (2015) Rádios comunitárias e desenvolvimento sustentável: mapa digital como prospecção de cenário da comunicação comunitária em áreas de conflito socioambiental na Amazônia. XXXVIII Congresso Brasileiro de Ciências da Comunicação, Intercom: Sociedade Brasileira de Estudos Interdisciplinares da Comunicação Rio de Janeiro/RJ, 1-15.

Volpato, M. O. (2008) Rádio comunitária, educomunicação e educação ambiental: pistas teórico-conceituais. S/r.

Xavier, F. V., \& Xavier, F. V. (2016) Abordagem dos problemas ambientais urbanos no ensino fundamental - estudo de caso. XVIII Encontro Nacional de Geógrafos. 